\title{
PERDAS DE ÁGUA E SOLO SOB DIFERENTES PADRÕES DE CHUVA SIMULADA E CONDIÇÕES DE COBERTURA DO SOLO
}

\section{DANIEL F. DE CARVALHO ${ }^{1}$, WANDERLEY DE J. SOUZA ${ }^{2}$, MARINALDO F. PINTO ${ }^{3}$, JOÃO R. DE OLIVEIRA ${ }^{4}$, JOSÉ G. M. GUERRA ${ }^{5}$}

\begin{abstract}
RESUMO: Este trabalho foi realizado com o objetivo de determinar as perdas de solo e água em um Argissolo Vermelho-Amarelo, submetido a quatro diferentes padrões de precipitação de chuva simulada e duas condições de cobertura: área com solo descoberto e com palhada após plantio de milho. O experimento foi conduzido no Campo Experimental da Embrapa-Agrobiologia, localizado no município de Seropédica-RJ, e consistiu na aplicação de chuvas simuladas com diferentes padrões, caracterizados como avançado (AV), intermediário (IN), atrasado (AT) e constante (CT), em uma área amostral de 0,80 $\mathrm{m}$ de largura por 1,0 $\mathrm{m}$ de comprimento. Utilizando um simulador de chuvas portátil, foram aplicadas chuvas com $30 \mathrm{~mm}$ de lâmina total durante 60 minutos. Nos padrões com intensidade variada, o pico de precipitação foi de $110 \mathrm{~mm} \mathrm{~h}^{-1}$. Os resultados obtidos possibilitaram concluir que a cobertura do solo com resíduos de milho reduziu substancialmente as taxas e perdas de água e solo, principalmente para o padrão de chuva constante, indicando que a palhada deixada sobre o solo após a colheita auxilia de maneira efetiva no controle da erosão.
\end{abstract}

PALAVRAS - CHAVE: erosão hídrica, padrões de precipitação, simulação de chuva.

\section{WATER AND SOIL LOSSES UNDER DIFFERENT PATTERNS OF SIMULATED RAINFALL AND SOIL COVER CONDITIONS}

\begin{abstract}
This study was carried out in order to determine the soil and water losses in a Yellow-red Ultisol, under four different rainfall patterns and two conditions of soil cover: area with soil uncovered and with straw after corn planting. The experiment was conducted at the experimental field of Embrapa Agrobiologia, located at Seropédica municipality, State of Rio de Janeiro, Brazil. The treatments consisted in application of simulated rainfall using variable intensity classified in different patterns as: advanced (AV), intermediate (IN), delayed (AT), and constant (CT), in a plots with $0.8 \mathrm{~m}$ of width and $1.0 \mathrm{~m}$ of length. Using a portable rainfall simulator rainfall with $30 \mathrm{~mm}$ total depth during 60 minutes was applied. For the patterns with varied intensity, the peak of precipitation was $110 \mathrm{~mm} \mathrm{~h}^{-1}$. The results showed the cover of the soil with corn stubble substantially reduced the rates and the soil and water losses, mainly for the pattern of constant rainfall, indicating that the residues left on the ground after harvest helps effectively in the erosion control.
\end{abstract}

KEYWORDS: water erosion, patterns rainfall, rainfall simulation

\section{INTRODUÇÃO}

A chuva é o fator climático mais importante com relação à erosão, cuja ação maléfica ocorre quando é rompida a estabilidade adquirida ao longo do tempo entre o solo, a vegetação e os organismos do solo, em geral pela intervenção do homem (MEHL, 2000). BEUTLER et al. (2003) comentam que a chuva e a enxurrada, combinadas, são os principais agentes ativos da erosão

\footnotetext{
${ }^{1}$ Prof. Associado IV, Depto. de Engenharia, Instituto de Tecnologia, UFRRJ, Seropédica - RJ, Fone: (0XX21) 2682-1864, carvalho@ufrrj.br. Bolsista do CNPq.

${ }^{2}$ Prof. Adjunto da UFBA, Doutor pela ESALQ/USP, Piracicaba - SP, Fone: (0XX19) 3429.4217, wjsouza@esalq.usp.br.

${ }^{3}$ Especialista em Laboratório da Universidade de São Paulo e Doutorando do curso de Irrigação e Drenagem da ESALQ/USP, Piracicaba - SP, Fone: (OXX19) 3429.4217, marinald@esalq.usp.br.

${ }^{4}$ INCRA/SR.14/AC, Rua Santa Inês, 135, Rio Branco - AC, joao.oliveira@rbo.gov.incra.br.

${ }^{5}$ Pesquisador da Embrapa Agrobiologia, Fone: (0xx21) 2682.1230, gmguerra@ cnpab.embrapa.br.

Recebido pelo Conselho Editorial em: 24-9-2009

Aprovado pelo Conselho Editorial em: 23-4-2012
} 
hídrica. A associação desses agentes a outros fatores relativos às condições do terreno determina a intensidade de degradação do solo.

As chuvas naturais apresentam consideráveis alterações em termos de intensidade durante sua ocorrência, podendo ser classificadas em diferentes padrões ou perfis de acordo com a intensidade e a duração. Além disso, sabe-se que as características das chuvas mudam de região para região (KELLER FILHO et al., 2005), obtendo-se diferentes padrões de chuva em cada uma delas.

Os principais fatores relacionados às condições do terreno, que determinam a intensidade do processo erosivo, estão diretamente relacionados à erodibilidade do solo, que é determinada por fatores como declividade, capacidade de infiltração de água no solo, rugosidade superficial porcentagem de cobertura do solo. De acordo com VOLK \& COGO (2008), o resultado final é consequência da interação de fatores químicos, físicos, biológicos e mineralógicos do solo. De acordo com CASTRO et al. (2006), a condição de cobertura associada à rugosidade superficial do solo proporcionam condições físicas importantes no que se refere à redução da erosão hídrica, uma vez que atua na dissipação da energia de impacto das gotas da chuva, enquanto a rugosidade é responsável pela redução da velocidade da água no escoamento superficial.

As propriedades físicas do solo influenciam diretamente sobre o processo erosivo, principalmente aquelas que afetam a taxa de infiltração e permeabilidade e aquelas que influenciam sobre a resistência do solo às forças de dispersão, salpico e transporte. No mesmo sentido, BERTOL et al. (2008) comentam que as propriedades físicas do solo influenciam na erosão hídrica, podendo as mesmas serem alteradas por meio do preparo mecânico. VOLK et al. (2004), estudando a influência das condições físicas de superfície e subsuperfície do solo submetido a diferentes condições de manejo, observaram que a incorporação sistemática de resíduos culturais reduziu em $25 \%$ a perda de solo por erosão hídrica, quando comparada com sua retirada. Segundo os autores, as condições físicas de superfície e subsuperfície do solo que governam as perdas de solo por erosão hídrica são bem distintas daquelas que governam as perdas de água pelo mesmo fenômeno. SILVA et al. (2005) observaram que alguns atributos físicos do solo são modificados em função do manejo, fazendo com que as perdas de solo e água sejam mais acentuadas no sistema de cultivo convencional. Neste sistema de preparo, a camada compactada do solo é encontrada em maiores profundidades quando comparada ao sistema de plantio direto, no qual a pressão exercida pelas máquinas propicia a compactação em menores profundidades.

Em estudos de conservação e manejo do solo e da água, além das parcelas experimentais de perda de solo sob chuva natural, têm sido muito empregados os infiltrômetros de aspersão ou simuladores de chuva (PANACHUKI et al., 2006). Estes equipamentos são ferramentas de pesquisa projetadas para a aplicação de água por aspersão de forma similar às chuvas naturais. Mediante caracterização do diâmetro médio, da distribuição e da velocidade terminal das gotas para diferentes intensidades de precipitação e pressão de serviço, a utilização desses equipamentos constitui uma importante ferramenta para agilizar a obtenção de dados e a quantificação das perdas de solo e água, possibilitando a avaliação de tipos de manejo de solo, da cobertura e de sistemas de controle de erosão (CARVALHO et al., 2005).

Diante do exposto, desenvolveu-se este trabalho com o objetivo de avaliar as perdas de água e solo em um Argissolo Vermelho-Amarelo, utilizando diferentes padrões de chuvas simuladas, sob duas condições de manejo do terreno: preparado no sentido morro abaixo com solo descoberto e utilizando palhada de milho como cobertura morta.

\section{MATERIAL E MÉTODOS}

O presente estudo foi realizado em um Campo Experimental da Embrapa Agrobiologia, localizada em Seropédica - RJ, latitude $22^{\circ} 48^{\prime}$ sul e longitude $43^{\circ} 41^{\prime}$ oeste. O solo é classificado como Argissolo Vermelho-Amarelo e apresenta declividade média de $0,09 \mathrm{~m} \mathrm{~m}^{-1}$. 
Na Tabela 1, estão apresentadas algumas características do horizonte superficial do solo da área experimental (OLIVEIRA, 2007), cujas análises foram feitas antes da realização dos testes.

TABELA 1. Características físicas e químicas do horizonte $\mathrm{A}$ do solo $(0-0,16 \mathrm{~m})$ da área experimental. Physical and chemical characteristics of the soil A horizon (0$0,16 \mathrm{~m}$ ) of the experimental area.

\begin{tabular}{|c|c|c|c|c|c|c|c|}
\hline \multirow[b]{2}{*}{$\begin{array}{c}\mathrm{Dp} \\
\left(\mathrm{kg} \mathrm{dm}^{-3}\right)\end{array}$} & \multirow[b]{2}{*}{$\begin{array}{c}\text { Ds } \\
\left(\mathrm{kg} \mathrm{dm}^{-3}\right)\end{array}$} & \multirow[b]{2}{*}{$\begin{array}{l}\mathrm{Dm}^{*} \\
(\mathrm{~mm})\end{array}$} & \multirow{2}{*}{$\begin{array}{l}\text { IEA** } \\
(\mathrm{mm})\end{array}$} & \multicolumn{4}{|c|}{ Composição granulométrica $\left(\mathrm{g} \mathrm{kg}^{-1}\right)$} \\
\hline & & & & $\begin{array}{c}\text { Areia } \\
0,05-2,0 \mathrm{~mm}\end{array}$ & 0,002 & $\mathrm{~mm}$ & $\begin{array}{l}\text { Argila total } \\
<0,002 \mathrm{~mm}\end{array}$ \\
\hline 2,67 & 1,34 & 3,52 & 92,48 & 580 & & & 260 \\
\hline \multirow{2}{*}{\multicolumn{2}{|c|}{$\begin{array}{c}\mathrm{pH} \\
\mathrm{H}_{2} \mathrm{O}\end{array}$}} & $\mathrm{Al}^{+++}$ & $\mathrm{Ca}^{++}$ & $\mathrm{Mg}^{++}$ & $\mathrm{P}^{++++}$ & $\mathrm{K}^{+}$ & $\mathrm{MO}$ \\
\hline & & \multicolumn{3}{|c|}{$\mathrm{cmol}_{\mathrm{c}} \mathrm{dm}^{-3}$} & \multicolumn{2}{|c|}{$\left(\mathrm{mg} \mathrm{dm}^{-3}\right)$} & $\left(\mathrm{g} \mathrm{kg}^{-1}\right)$ \\
\hline \multicolumn{2}{|c|}{4,9} & 0,20 & 2,8 & 1,3 & 4,0 & 47,0 & 18,0 \\
\hline
\end{tabular}

Para a condução do experimento, foi utilizado um simulador de chuvas portátil equipado com bicos VeeJet 80-150, que foi inicialmente calibrado a fim de simular chuvas com características próximas às da chuva natural. Foram aplicadas chuvas em um tempo de 60 minutos e lâmina precipitada de $30 \mathrm{~mm}$, que representa a lâmina média das chuvas intensas ocorridas na região de Seropédica - RJ (CARVALHO et al., 2005). Além da chuva simulada com intensidade constante (CT), foram estudados os padrões de chuva avançado (AV), intermediário (IN) e atrasado (AT), que, segundo MELH (2000), são classificados de acordo com a posição de ocorrência do pico de maior intensidade em relação ao tempo total do evento. O AV caracteriza-se quando a maior intensidade ocorre em um período de tempo menor do que $30 \%$ a partir do tempo inicial da chuva em relação ao tempo de duração total; o IN, quando a maior intensidade ocorre entre 30 e $60 \%$ do tempo total da chuva; e o AT, quando a maior intensidade ocorre passados mais de $60 \%$ do tempo total de duração do evento.

O pico de maior intensidade de precipitação (Ip) para os padrões AV, IN e AT foi de $110 \mathrm{~mm} \mathrm{~h}^{-1}$, também determinado por CARVALHO et al. (2005), com base no registro das chuvas intensas ocorridas na região de Seropédica - RJ. Na Figura 1, constam os perfis de intensidade de precipitação em função do tempo, utilizados nos ensaios.

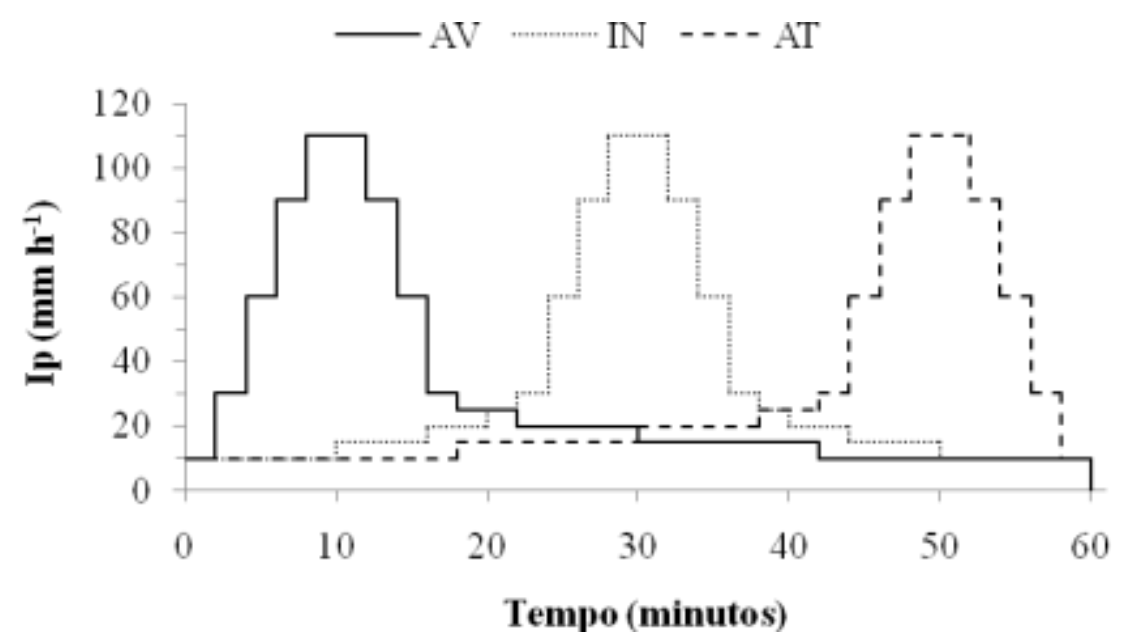

FIGURA 1. Perfis de intensidade de precipitação para os padrões Avançado (AV), Intermediário (IN), Atrasado. Rainfall intensity profile for the precipitation patterns advanced (AV), intermediate (IN) and delayed (AT).

A área experimental encontrava-se inativa havia cerca de 20 anos e era ocupada por gramíneas. Sendo assim, antes da primeira fase de testes com o simulador (solo exposto), foi 
realizada uma subsolagem, seguida do preparo convencional, com uma aração e duas gradagens, realizado no sentido do declive do terreno, buscando simular as condições críticas praticadas em propriedades rurais.

Após a execução destes testes, a mesma área foi cultivada com milho, semeado em sulcos no sentido do preparo do terreno, com espaçamento de 1,0 m entre linhas e sete plantas por metro linear. Trinta dias após a colheita, foi realizada a segunda etapa de testes sobre o solo coberto por, aproximadamente, 8,0 t ha ${ }^{-1}$ de palhada do milho (solo com cobertura morta), cujo percentual de cobertura foi de aproximadamente 62\%, determinado conforme LOPES et al. (1987).

A variabilidade das características físicas do solo no local dos testes foi analisada antes dos ensaios com o simulador de chuvas para solo desnudo e com cobertura, determinando-se a densidade do solo (método do anel volumétrico), macro e microporosidade (método da mesa de tensão) e porosidade total, seguindo a metodologia preconizada pela EMBRAPA (1997), com amostragem do solo em diferentes profundidades.

Após o início do experimento (primeira e segunda etapas), toda a área foi coberta com uma lona plástica, com o objetivo de manter a uniformidade das parcelas experimentais durante a realização dos testes (MEHL, 2000).

Em virtude de as variáveis físicas avaliadas não apresentarem diferenças estatísticas entres os locais onde seriam aplicados os tratamentos, o experimento foi conduzido em delineamento inteiramente casualizado, com quatro tratamentos, que consistiram nos padrões de precipitação (AV, IN, AT e CT) e cinco repetições, totalizando 20 parcelas de $0,80 \mathrm{~m}^{2}$, delimitadas lateralmente por chapas de ferro de $0,25 \mathrm{~m}$, cravadas a $0,10 \mathrm{~m}$ no solo.

Antes da aplicação de cada evento pluviométrico, procedeu-se a um pré-molhamento com uma chuva de 15 a $20 \mathrm{~mm} \mathrm{~h}^{-1}$, aplicada pelo simulador, durante um tempo suficiente para umedecer o solo sem que houvesse escoamento superficial, objetivando-se uniformizar a umidade do solo em toda a área experimental (PANACHUKI et al., 2006). Após 10 minutos, o simulador era novamente acionado, simulando as chuvas previstas de acordo com os diferentes padrões, tomando-se o cuidado de mantê-lo protegido lateralmente através de lona plástica, a fim de evitar a interferência do vento. No momento dos testes, o simulador de chuva foi posicionado sobre as parcelas e regulado para aplicar uma lâmina com a intensidade desejada.

Para cada tratamento especificado, as amostras da enxurrada foram coletadas em recipientes de volume conhecido, em um intervalo de tempo de 2 minutos. Os instantes de amostragem da enxurrada foram distribuídos de modo que abrangessem cada intensidade de precipitação que compôs os padrões de precipitação.

No final de cada teste, as amostras das enxurradas coletadas foram imediatamente agrupadas e encaminhadas ao laboratório, sendo transferidas para recipientes de vidro de massa conhecida, e pesadas em balança de precisão. Posteriormente, foi retirada uma pequena alíquota do material sobrenadante e proporcional ao volume escoado em cada recipiente, a qual foi colocada em congelador até que a etapa de campo fosse concluída. A solução restante em cada recipiente foi levada à estufa de circulação forçada a $60^{\circ} \mathrm{C}$, até massa constante, para a quantificação das perdas de solo e água.

A estimativa da quantidade de solo e água presentes em cada amostra foi realizada, determinando-se inicialmente a massa de sedimentos escoada, por meio da pesagem direta de cada recipiente, após a evaporação da água em estufa. A massa de água foi obtida subtraindo a massa de sólidos (g) presente após a evaporação em estufa, da massa total da enxurrada de cada amostra (descontada a massa do recipiente de vidro). Os resultados foram submetidos às análises da variância e de comparação de médias, pelo teste de Tukey, a 5\%. Foram também realizadas análises de nutrientes nos sedimentos, empregando-se a mesma metodologia utilizada no sobrenadante da enxurrada. As perdas totais de nutrientes nos sedimentos $\left(\mathrm{g} \mathrm{m}^{-2}\right)$ foram calculadas pelo produto das concentrações dos elementos, nos sedimentos, pela massa total perdida por unidade de área. 


\section{RESULTADOS E DISCUSSÃO}

Nas Figuras 2 e 3, apresentam-se as taxas de perdas de água e solo, respectivamente, ocorridas sob influência dos padrões de precipitação, utilizando-se de área sem e com cobertura de palha de milho.

Utilizando o solo sem cobertura, o padrão CT apresentou taxas de perdas de solo e água crescentes até determinado tempo após o início da chuva, atingindo o ponto máximo, com tendência ao decréscimo. Resultados similares foram apresentados por CASSOL \& LIMA (2003), quando aplicaram uma chuva simulada com intensidade constante de $60 \mathrm{~mm} \mathrm{~h}^{-1}$ durante 70 minutos, em solo descoberto ou com a palha incorporada, e evidenciaram que as taxas de perda de solo são crescentes até um determinado ponto, apresentando, a partir daí comportamento decrescente.

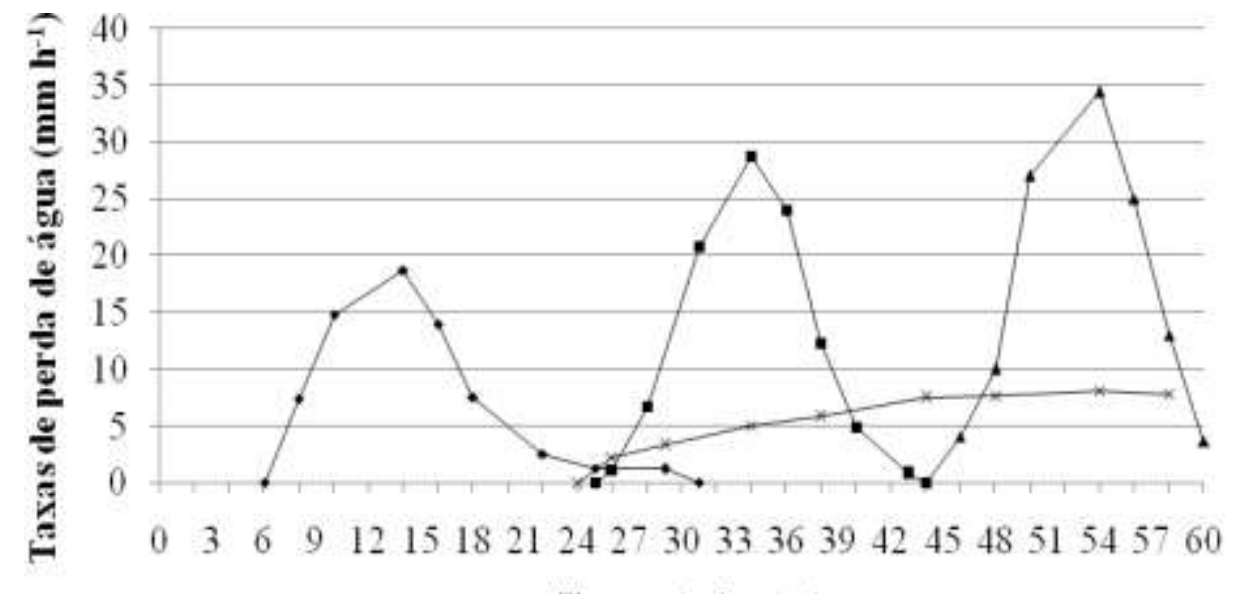

Tempo (minutos)
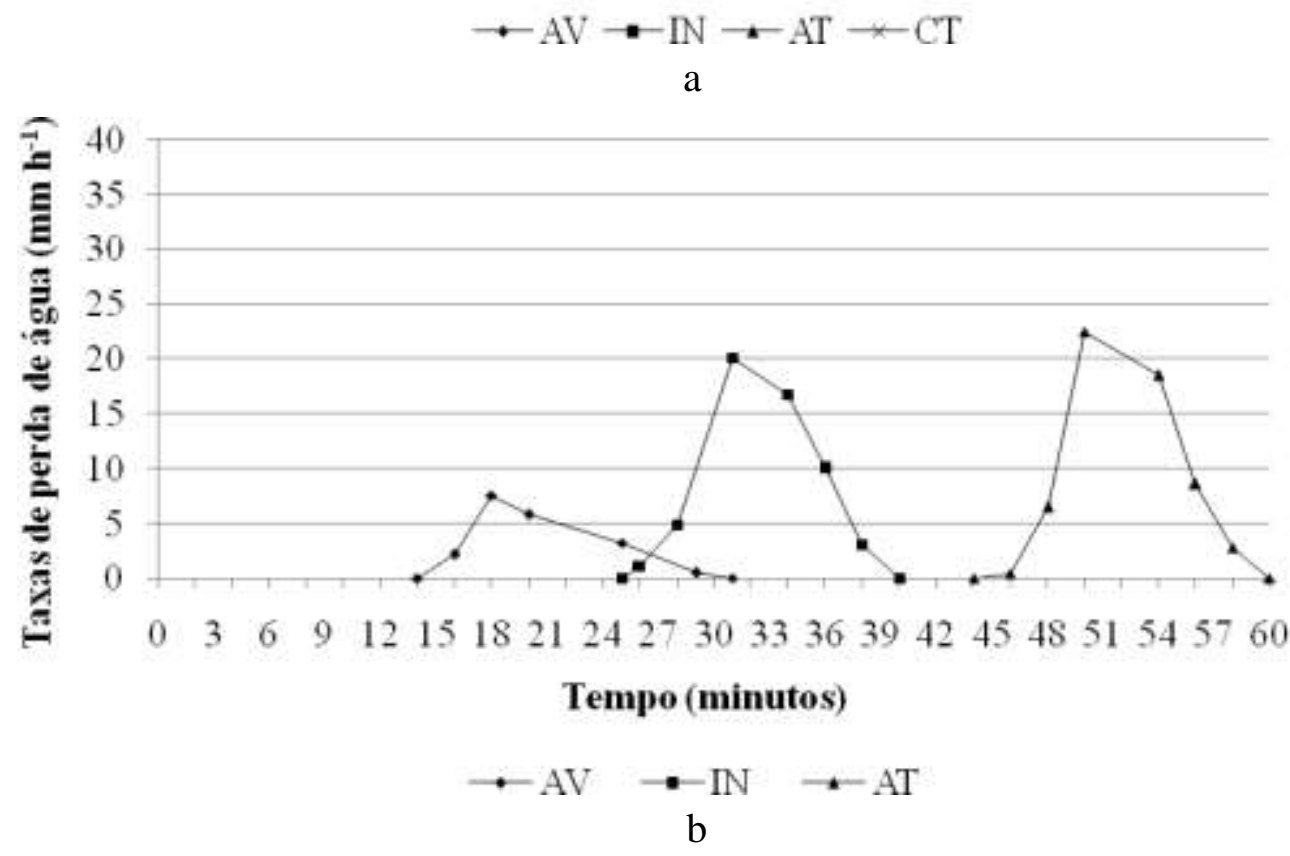

FIGURA 2. Taxas de perda de água $\left(\mathrm{mm} \mathrm{h}^{-1}\right)$ nos padrões de precipitação Avançado (AV), Intermediário (IN), Atrasado (AT) e Constante (CT), no solo sem (a) e com cobertura morta (b). Water loss rates $\left(\mathrm{mm} \mathrm{h}^{-1}\right)$ using the precipitation patterns advanced (AV), intermediate (IN), delayed (AT) and constant (CT) in the soil without (a) and with plant residue (b). 

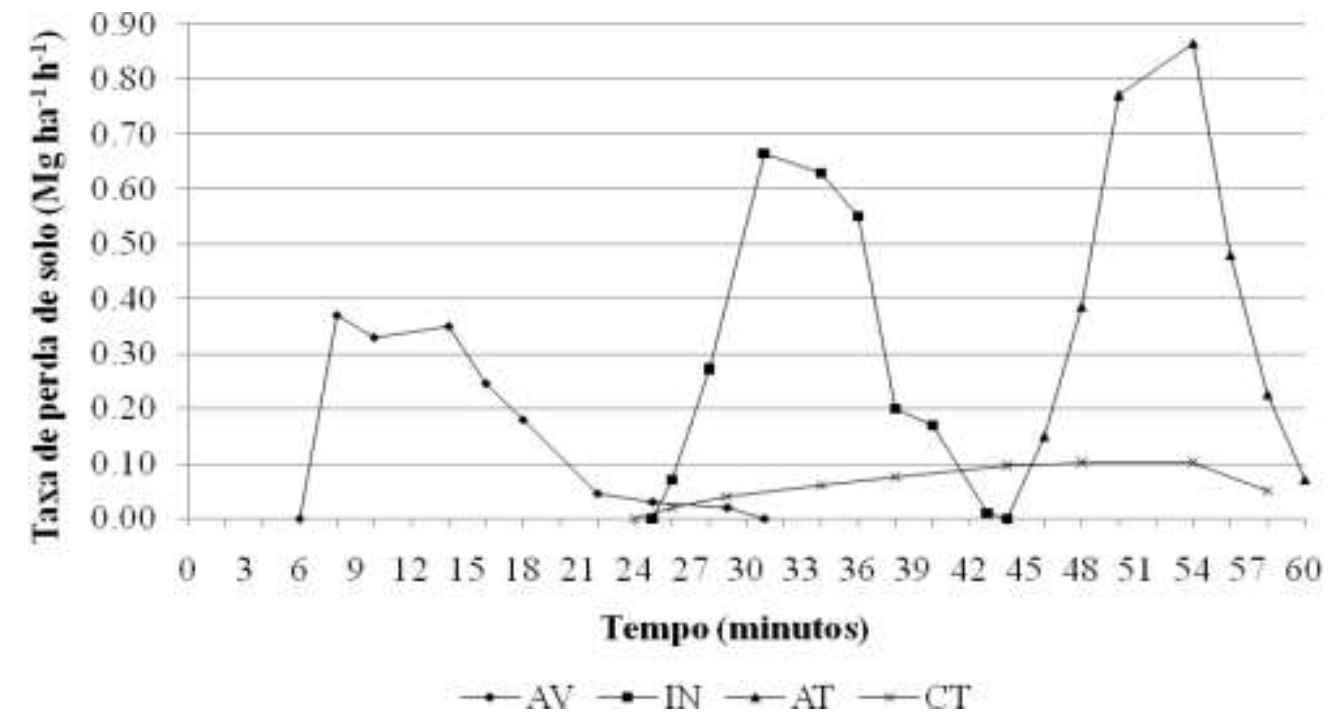

a

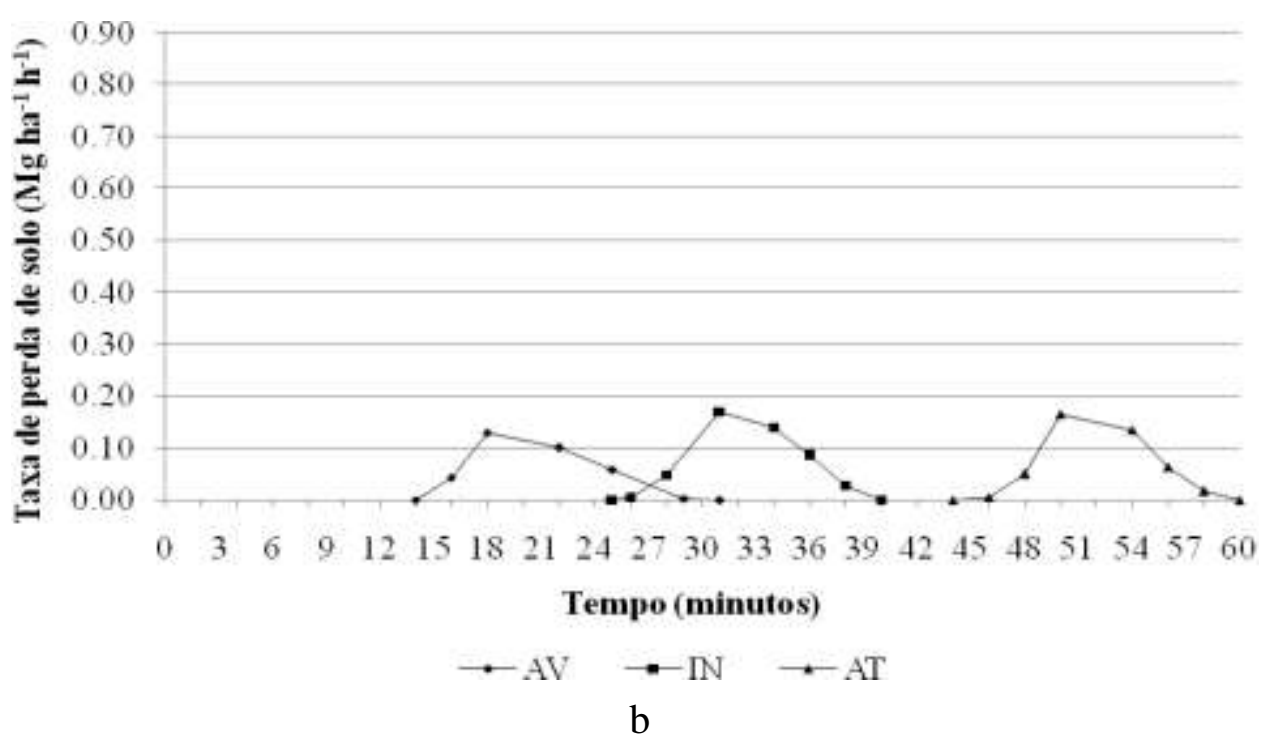

FIGURA 3. Taxas de perda de Solo $\left(\mathrm{Mg} \mathrm{ha}^{-1} \mathrm{~h}^{-1}\right)$ nos padrões de precipitação Avançado (AV), Intermediário (IN), Atrasado (AT) e Constante (CT), no solo sem (a) e com cobertura morta (b). Soil loss rates $\left(\mathrm{Mg} \mathrm{ha}^{-1} \mathrm{~h}^{-1}\right)$ using the precipitation patterns advanced (AV), intermediate (IN), delayed (AT) and constant (CT) in the soil without (a) and with plant residue (b).

Em ambas as condições de cobertura do solo, quando se aplicaram altas intensidades de precipitação ou quando se aproximou do ponto de máxima intensidade, observaram-se altos valores de escoamento. Isso se explica pela própria dinâmica do teste, pois quando a aplicação da chuva atinge intensidades superiores à taxa de infiltração do solo, há um acúmulo de água na superfície e, consequentemente, o escoamento superficial nesses pontos. Além disso, chuvas com altas intensidades tende a aumentar as perdas de solo devido à redução da taxa de infiltração provocada pelo selamento da superfície (BRANDÃO et al., 2007).

A palha de milho deixada sobre o solo dificultou o movimento da água pela pendente, reduzindo sua energia cinética e os impactos diretos das gotas de chuva, diminuindo o poder erosivo da enxurrada. Estes resultados corroboram aqueles encontrados por CASTRO et al. (2006).

Na Tabela 2, estão apresentados os valores das taxas máximas de perda de solo e de água para os padrões de precipitação. Independentemente das condições de cobertura do solo, os padrões de precipitação AV, IN e AT não influenciaram, de forma significativa, as taxas máximas de perda de 
solo e de água. Apesar de a área de estudo ser considerada homogênea, a pequena dimensão da parcela experimental $\left(0,80 \mathrm{~m}^{2}\right)$ pode ter favorecido a condução do experimento em locais distintos quanto à presença de caminhos preferenciais para a movimentação da água no perfil do solo, influenciando, de forma decisiva, na obtenção dos altos coeficientes de variação para os valores de taxas máximas de perdas de solo e água.

Em condições de solo coberto por resíduos culturais de milho, os padrões influenciaram significativamente sobre os picos de perda de solo, não sendo verificadas perdas durante a aplicação das chuvas sob padrão constante de precipitação.

TABELA 2. Taxa máxima de perda de solo e água com os padrões de precipitação em diferentes condições de cobertura do solo. Maximum rate of soil and water loss with the precipitation patterns in different conditions of soil cover.

\begin{tabular}{|c|c|c|c|c|}
\hline \multirow{2}{*}{$\begin{array}{l}\text { Padrões de } \\
\text { Precipitação }\end{array}$} & \multicolumn{2}{|c|}{$\begin{array}{l}\text { Taxa Máxima de Perda de Solo } \\
\qquad\left(\mathrm{Mg} \mathrm{ha}^{-1} \mathrm{~h}^{-1}\right)\end{array}$} & \multicolumn{2}{|c|}{$\begin{array}{l}\text { Taxa Máxima de Perda de Água } \\
\qquad\left(\mathrm{mm} \mathrm{h}^{-1}\right)\end{array}$} \\
\hline & SSC & SCC & SSC & SCC \\
\hline Avançado & $0,337 \mathrm{Aa}$ & $0,132 \mathrm{Aa}$ & $18,40 \mathrm{Aa}$ & $7,40 \mathrm{Aa}$ \\
\hline Intermediário & $0,662 \mathrm{Aa}$ & $0,168 \mathrm{Ab}$ & $28,60 \mathrm{Aa}$ & $20,20 \mathrm{Aa}$ \\
\hline Atrasado & $0,862 \mathrm{Aa}$ & $0,161 \mathrm{Ab}$ & $34,40 \mathrm{Aa}$ & $22,10 \mathrm{Aa}$ \\
\hline Constante & $0,099 \mathrm{~A}$ & $*$ & $8,30 \mathrm{~A}$ & $*$ \\
\hline$\overline{\text { C.V. }(\%)}$ & 88,71 & 59,04 & 98,04 & 67,08 \\
\hline
\end{tabular}

Médias seguidas de mesma letra, maiúscula na coluna e minúscula na linha, não diferem entre si, pelo teste de Tukey, a 5\%. SSC Solo sem cobertura morta, SCC - Solo com cobertura morta. * não foi observado escoamento superficial.

Na Tabela 3, estão apresentados os resultados estatísticos das perdas acumuladas de solo e água para cada padrão de precipitação, em diferentes condições de cobertura do solo. Tanto no solo sem cobertura quanto no solo com cobertura, não foram observadas diferenças estatísticas entre as perdas provocadas pelos diferentes padrões de precipitação.

TABELA 3. Resultados das perdas acumuladas de solo $\left(\mathrm{Mg} \mathrm{ha}^{-1}\right)$ e água $\left(\mathrm{L} \mathrm{m}^{-2}\right)$ em diferentes condições de cobertura do solo. Results of soil and water cumulative losses in different conditions of soil cover.

\begin{tabular}{llccc}
\hline \multicolumn{1}{c}{ Padrões de } & \multicolumn{2}{c}{ Perda Acumulada de Solo } & \multicolumn{2}{c}{ Perda Acumulada de Água } \\
\cline { 2 - 5 } \multicolumn{1}{c}{ Precipitação } & SSC & SCC & SSC & SCC \\
\hline Avançado & $0,067 \mathrm{Aa}$ & $0,017 \mathrm{Aa}$ & $2,8 \mathrm{Aa}$ & $0,9 \mathrm{Aa}$ \\
Intermediário & $0,108 \mathrm{Aa}$ & $0,021 \mathrm{Ab}$ & $3,9 \mathrm{Aa}$ & $2,5 \mathrm{Aa}$ \\
Atrasado & $0,125 \mathrm{Aa}$ & $0,020 \mathrm{Ab}$ & $4,8 \mathrm{Aa}$ & $2,7 \mathrm{Aa}$ \\
Constante & $0,048 \mathrm{~A}$ & $*$ & $3,9 \mathrm{~A}$ & $*$ \\
\hline
\end{tabular}

Médias seguidas de mesma letra, maiúscula na coluna e minúscula na linha, não diferem entre si, pelo teste de Tukey, a 5\%. SSC Solo sem cobertura morta, SCC - Solo com cobertura morta. * não foi observado escoamento superficial.

Sob a condição do solo com cobertura, os padrões de precipitação AV, IN e AT proporcionaram maiores valores de perda de solo e água em relação ao padrão CT, que por sua vez não proporcionou escoamento e, consequentemente, perdas de solo e água. Esse resultado confirma a hipótese de que este padrão, extensamente empregado em estudos de erosão hídrica no Brasil, não retrata de forma coerente os processos erosivos influenciados pelo padrão natural das chuvas. Estas diferenças na perda de solo entre condições de cobertura indicam que, na presença de proteção da superfície do solo contra os agentes erosivos, a cobertura superficial tem efeito importante na retenção dos sedimentos da erosão.

As perdas acumuladas de solo refletiram de forma mais acentuada sobre as diferenças existentes entre os padrões de precipitação do que para as perdas acumuladas de água. Estes 
resultados estão de acordo com BEUTLER et al. (2003), que concluíram que as perdas de solo são mais afetadas pelo sistema de preparo e cultivo do que as perdas de água.

Na condição de cobertura do solo com palha, os padrões AT e IN apresentaram perda de solo inferior ao solo sem cobertura. Como no padrão AT e IN o pico de intensidade de precipitação e escoamento superficial ocorrem quando o solo se encontra com alta umidade, o processo erosivo é favorecido em condição de solo sem cobertura. Para a condição de solo com cobertura, a energia cinética das gotas, a turbulência da enxurrada e, consequentemente, o arraste de partículas de solo são reduzidos pela palhada.

Os dados mostram que o padrão CT apresentou as menores perdas acumuladas de solo e água, indicando que chuvas com intensidade constante de $30 \mathrm{~mm} \mathrm{~h}^{-1}$ propiciaram menor influência nas perdas de solo e água, para o solo avaliado. Portanto, é possível inferir que, para as condições deste estudo, taxas de aplicação de água inferiores a $30 \mathrm{~mm} \mathrm{~h}^{-1}$ somente provocarão escoamento expressivo em longos tempos, sendo úteis, inclusive, para um melhor planejamento e manejo de sistemas de irrigação.

O uso da cobertura com resíduos de milho proporcionou redução expressiva nas perdas de solo com os padrões IN, AT e CT, o que não aconteceu em mesma magnitude com as perdas de água, entre os diferentes padrões, cessando totalmente o escoamento para o padrão CT. Tal comportamento pode ser explicado em virtude das maiores velocidades de escoamento superficial, que ocorreram no solo sem cobertura, aliado ao preparo no sentido do declive. Essas características favoreceram o aumento no volume de solo desagregado pela formação de pontos preferenciais de escoamento no terreno que, por sua vez, proporcionou aumento na capacidade de transporte. Resultados semelhantes foram obtidos por CASTRO et al. (2006), que estudaram a erosão hídrica sob diferentes condições de preparo e cobertura do solo. Os autores evidenciaram que as perdas de água não foram tão influenciadas pela cobertura morta quanto as perdas de solo. Isso ocorre porque a presença de cobertura morta no solo protege sua superfície contra a ação de impacto direto das gotas da chuva, evitando ou diminuindo a desagregação inicial de suas partículas e, consequentemente, seu transporte e a perda total de solo. A cobertura deve ser analisada associada à rugosidade do solo; juntos, estes fatores controlam o carreamento de solo, reduzindo a perda acumulada deste; por outro lado, a perda acumulada de água não reduz na mesma proporção. Neste último caso, a cobertura do solo assume papel relevante, podendo evitar a formação de crosta superficial que diminui a capacidade de infiltração do solo. VOLK (2006), estudando indicadores de qualidade para a redução da erosão hídrica, utilizando um simulador de chuva, concluiu que as perdas de água não sofreram influência significativa do manejo dos resíduos culturais no solo.

Os resultados obtidos nesta pesquisa, para os padrões IN e AT, estão de acordo com os encontrados por INÁCIO et al. (2007), BEZERRA \& CATALICE (2006) e MARTINS FILHO et al. (2009), nos quais a cobertura vegetal foi capaz de reduzir a perda total de solo em entressulcos, em decorrência do efeito da proteção promovida pela cobertura na redução da desagregação do solo.

\section{CONCLUSÕES}

As perdas totais de solo e água para os diferentes padrões de precipitação não apresentaram diferenças significativas, tanto em solo nu, como em solo com cobertura nas condições desta pesquisa.

Para os padrões IN e AT, a cobertura do solo com resíduos de milho reduziu substancialmente as taxas máximas de perdas de solo e as perdas acumuladas de solo, indicando que, sob tais condições, a palhada deixada sobre o solo após a colheita auxilia de maneira efetiva no controle da erosão, principalmente em terras cultivadas em declive.

A condição de manejo da cobertura do solo com palha de milho (62\% de cobertura), sob preparo morro abaixo, foi suficiente para impedir o escoamento superficial no padrão de chuva CT. 


\section{REFERÊNCIAS}

BERTOL, I.; ZOLDAN JÚNIOR, W.A.; FABIAN, E.L.; ZAVASCHI, E.; PEGORARO, R.; GONZÁLEZ, A.P. Efeito de escarificação e da erosividade de chuvas sobre algumas variáveis de valores de erosão hídrica em sistemas de manejo de um Nitossolo Háplico. Revista Brasileira de Ciência do Solo, Viçosa-MG, v.32, n.2, p.747-757, 2008.

BEUTLER, J.F.; BERTOL, I.; VEIGA, M.; WILDNER, L.P. Perdas de solo e água num Latossolo Vermelho Aluminoférrico submetido a diferentes sistemas de preparo e cultivo sob chuva natural. Revista Brasileira de Ciência do Solo, Viçosa-MG, v.27, n.3, p.509-517, 2003.

BEZERRA, S.A.; CANTALICE, J.R.B. Erosão entressulcos em diferentes condições de cobertura vegetal de solo, sob cultivo da cana-de-açúcar. Revista Brasileira de Ciência do Solo, Viçosa-MG, v.30, n.3, p.565-573, 2006.

BRANDÃO, V. dos S.; SILVA, D.D. da; RUIZ, H.A.; PRUSKI, F.F.; SCHAEFER, C.E.G.R.; MARTINEZ, M.A.; SILVA, E.O. Perdas de solo e caracterização física e micromorfológica de crostas formadas em solos sob chuva simulada. Engenharia Agrícola, Jaboticabal, v.27, n.1, p.129$138,2007$.

CARVALHO, D.F.; MONTEBELLER, C.A.; FRANCO, E.M.; VALCARCEL, R.; BERTOL, I. Padrões de precipitação e índices de erosividade para as chuvas de Seropédica e Nova Friburgo-RJ. Revista Brasileira de Engenharia Agrícola e Ambiental, Campina Grande, v.9, n.1, p.7-14, 2005.

CASSOL, A.E.; LIMA, V.S. de. Erosão em entressulcos sob diferentes tipos de preparo e manejo do solo. Pesquisa Agropecuária Brasileira, Brasília, v.38, n.1, p.117-124, 2003.

CASTRO, L.G.; COGO, N.P.; VOLK, L.B.S. Alterações na rugosidade superficial do solo pelo preparo e pela chuva e sua relação com a erosão hídrica. Revista Brasileira de Ciência do Solo, Viçosa-MG, v.30, n.2, p.339-352, 2006.

EMBRAPA. EMPRESA BRASILEIRA DE PESQUISA AGROPECUÁRIA. Manual de métodos de análise do solo. 2.ed. Rio de Janeiro: Centro Nacional de Pesquisas de Solos, 1997. 212 p.

INÁCIO, E.S.B.; CANTALICE, J.R.B.; NACIF, P.G.S.; ARAÚJO, Q.R.; BARRETO, A.C. Quantificação da erosão em pastagem com diferentes declives na microbacia do Ribeirão Salomea. Revista Brasileira de Engenharia Agrícola e Ambiental, Campina Grande, v.11, n.4, p.355-360, 2007.

KELLER FILHO, T.; ASSAD, E.D.; LIMA, P.R.S.R. Regiões pluviometricamente homogêneas no Brasil. Pesquisa Agropecuária Brasileira, Brasília, v.40, n.4, p.311-322, 2005.

LOPES, P.R.C.; COGO, N.P.; LEVIEN, R. Eficácia relativa de tipo e quantidade de resíduos culturais espalhados uniformemente sobre o solo na redução da erosão hídrica. Revista Brasileira de Ciência do Solo, Viçosa-MG, v.11, n.1, p.71-75, 1987.

MARTINS FILHO, M.V.; LICCIOTI, T.T.; PEREIRA, G.T.; MARQUES JÚNIOR, J.; SANCHEZ, R.B. Perdas de solo e nutrientes por erosão num Argissolo com resíduos vegetais de cana-deaçúcar. Engenharia Agrícola, Jaboticabal, v.29, n.1, p.8-18, 2009.

MEHL, H.U. Caracterização de padrões de chuvas ocorrentes em Santa Maria (RS) e sua relação com as perdas de solo e água em entressulcos. 2000. 53 f. Dissertação (Mestrado em Agronomia)Universidade Federal de Santa Maria, Santa Maria, 2000.

OLIVEIRA, J.R. Perdas de solo, água e nutrientes em um Argissolo Vermelho-Amarelo sob diferentes padrões de chuva simulada. 2007. 52 f. Dissertação (Mestrado em Ciência do Solo) Universidade Federal Rural do Rio de Janeiro, Seropédica, 2007.

PANACHUKI, E.; ALVES SOBRINHO, T.; VITORINO, A.C.T.; CARVALHO, D.F.; URCHEI M.A. Avaliação da infiltração de água no solo, em sistema de integração agricultura-pecuária, com uso de infiltrômetro de aspersão portátil. Acta Scientiarum, Maringá, v.28, n.1, p.129-137, 2006. 
SILVA, C.G.; ALVES SOBRINHO, T.; VITORINO, A.C.T.; CARVALHO, D.F. Atributos físicos, químicos e erosão hídrica entressulcos sob chuva simulada, em sistema de plantio direto e convencional. Engenharia Agrícola, Jaboticabal, v.25, n.1, p.144-153, 2005.

VOLK, L.B.S. Condições físicas da camada superficial do solo resultantes do seu manejo e indicadores de qualidade para redução da erosão hídrica e do escoamento superficial. 2006. $148 \mathrm{f}$. Tese (Doutorado em Ciência do Solo) - Universidade Federal do Rio Grande do Sul, Porto Alegre, 2006.

VOLK, L.B.S.; COGO, N.P. Inter-relação biomassa vegetal subterrânea-estabilidade de agregadoserosão hídrica em solo submetido a diferentes formas de manejo. Revista Brasileira de Ciência do Solo, Viçosa-MG, v.32, n.4, p.1.713-1.722, 2008.

VOLK, L.B.S.; COGO, N.P.; STRECK, E.V. Erosão hídrica influenciada por condições físicas de superfície e subsuperfície do solo resultantes de seu manejo, na ausência de cobertura vegetal. Revista Brasileira de Ciência do Solo, Viçosa-MG, v.28, p.763-774, 2004. 